the cultural characteristics of the parasite causing the nonulcerating oriental sore and those of another parasite which he discovered in an insect commonly found throughout India and eastwards as far as Japan. His methods are ingenious, and though he does not demonstrate that the new parasite in the insect dealt with has anything to do with oriental sore, his experiments suggest that man may probably be another host. Considering the second part of the paper as independent of the first, as in most respects it actually is, an inversion of the usual method of attacking parasitic diseases is suggested-finding the parasite first and the disease afterwards. A most original point about the paper is the way in which Captain Carter shows that this protozoon, demonstrably parasitic in a particular insect, is possibly, or even probably, parasitic in man, though not in rats and some other mammals. 3. Dr. Critien's paper on Infantile Leishmaniasis (Marda tal Biccia) in Malta, contains a number of careful observations upon this disease. His facts as to distribution and some other points, however, though numerous, are not sufficient to permit definite conclusions, and he claims no more for them than that they are suggestions as to the lines upon which further investigations are most likely to be profitable. He "puts on record " that marda tal biccia and infantile kala-azar are one and the same disease. 4 and 5 . The two papers on malaria by Dr. David Thomson give in detail a large number of most laborious observations. Some of them are of undoubted value. Perhaps the most interesting is the fluctuations in the percentage of leucocytes which persist in the patient, notwithstanding ample treatment with quinine, for a considerable time, sometimes for several months, after apparent cure. The nature of this fluctuation depends upon the nature of the fever from which the patient has suffered. 6. The note upon the relative immunity of strange and native races to yellow fever in countries where the disease is indigenous, by the late Sir Rubert Boyce, is of con. siderable interest, particularly to students of heredity Though many may not agree with the author as to the nature of the immunity enjoyed by the native races, they will certainly welcome the facts collected and thus placed at their dispcsal. 7. The bulk of Dr. Fantham's paper is occupied by a useful sketch of the known parasitic amobr of the intestine of man and a brief but good critical review of the previous observations upon them.

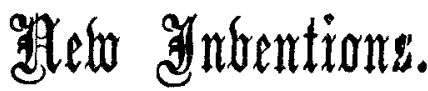

\section{IMPROVED MEANS OF DILATING CERTAIN PASSAGES.}

FIGS. 1 and 2 are instruments which, I submit, possess many advantages. Fig. 1 is a uterine and Fig. 2 is a male urethral dilator. Hitherto the great defect in expanding dilators was that we had no means of gauging force. Hence dilatation to desired degrees was at the expense of splitting - a heavy penalty. We cannot judge force by screws, nor is hand pressure so good as untiring gentle elastic pressure. Fig. 1 dilates the cervical canal by means of the elastic expansion of its long arms $A$, thus antagonising tonic resistance by tonic pressure. There is a scale not shown. The instrument is put into action after introduction by pressing the handles together to the extent desired and fixing them at that by the fly nut. $B$ lies against the external os and affords the point d'appui for gauze packing to keep the instrument in situ, the handles being supported on a pillow. Thus tents, always a nuisance and sometimes septic, may be dispensed with. Rapid dilatation may, of course, be used. Fig. 2 is a substitute for Kollmann's dilator. The posterior half of the anterior urethra is a funnel, widest at the bulb. No instrument ever used is capable of $d$ istending this widest part to the full extent without splitting the narrow part of the funnel. No instrument satisfactorily dilates the bulb, the chief site of infiltration, worst beginning strictures, and gleet. Nor do instruments passed beyond this site distend it owing to the smallness of balbomembranous junction. The arm $\mathrm{E}$ is long, hence it extends to the extreme end of the spongy urethra. Moreover, the arrangements of the semi-bulbs of the instrument permit them to pass through a narrow meatus, thus constitating a
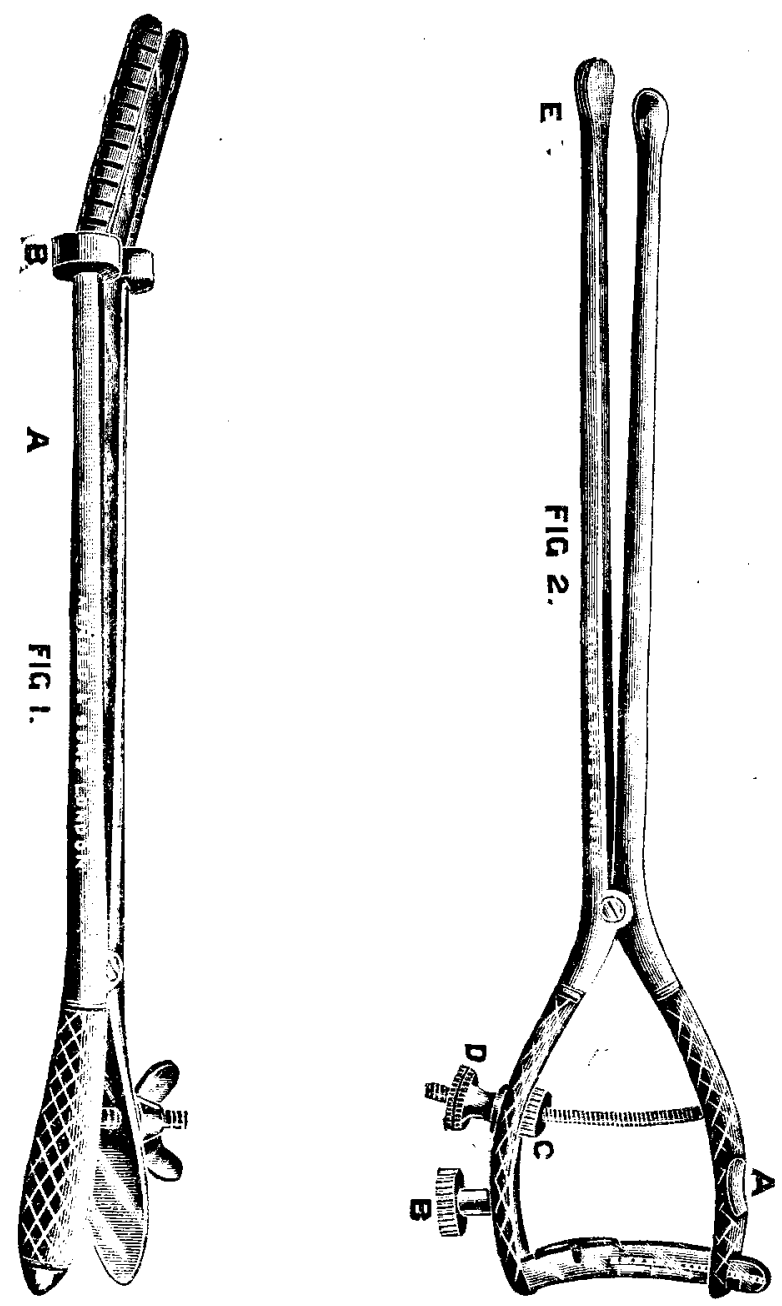

I rrge distending body behind it, and a urethrumeter if desired. This dilator, like the uterine, can be actuated by fingerpressure on $A$ and $B$, or by screw through $D$; there is a millimetre scale. The character of the arms is such that while the whole anterior urethra is uniformly dilated there is no splitting. The desired expansion is fixed beforehand by the nut $c$, and expansion is taken to this extent or not according to the resistance conveyed to the fingers or according to the patient's sensations.

The instruments were made originally by myself, but are now made in a more perfect way by Messrs. Arnold and Sons. Finsbury-pavement, E.C. JaMes MaCMUnN.

West End Hospital for Diseases of the Neryous System, Paralysis, and Epilepsy.-On Dec. 1st a number of ladies met at 5, Bryanston-square, on the invitation of Mrs. Ian Malcolm, to take steps for the formation of a ladies' guild. The chair was taken by Colonel the Hon. Charles S. H. D. Willoughby, treasurer of the hospital; the secretary, Mr. D. D. Kirkaldy, and the matron, Miss Catharine E. A. Thorpe, were also present, and a number of influential ladies. The chairman opened proceedings by giving a sketch of the hospital's work and by showing the service a ladies' guild would be to the hospital. The matron then entered into farther details regarding the advantages of such a guild, whose subdivisions might help the hospital in obtaining gifts of vegetables, flowers, poultry, and clothing. A resolution that a ladies' guild be formed was then carried unanimously and the following officers were elected :-President, Lady Violet Brassey ; honorary treasure:, Colonel Willoughby; honorary secretary, Miss Broadhurst; honorary secretary of Vegetable League, Lady Guernsey; honorary secretary of Olothing and Linen League, Miss Eiston. A committee was formed consisting of Mrs. Ian Malcolm, Mrs. Ferdinand Huth, Mrs. O. A. Ballance, Mrs. Harry Graham, and the honorary secretaries. 


\section{THE LANCET.}

\section{LONDON : SATORDAY, DECEMBER 16, 1911.}

\section{The National Insurance Bill.}

THE National Insurance Bill, receiving probably no modification at the hands of the House of Lords, will become law within the next few days, and the medical profession has to resolve what course should be pursued. We mast recollect that no one course can be equally acceptable to all the members of a highly organised calling. In this elaborate and far-reaching measure the interests of some practitioners are affected in one manner and the interests of other practitioners are affected in a totally different manner by the same section or sub-section of the measure. The Bill is quite clear with regard to the benefits that are to be received by the insured from the medical profession, quite clear that in return for definite contributions free medical service is to be supplied, but quite vague as to the payment of those who are to supply it. For these reasons, as well as because of a too general committal of the profession to an extension of the contract system, we have always considered that the medical profession should have pointed out from the very beginning that it would be impossible to arrange a satisfactory scheme of either distribution of medical benefits or payment of medical men unless adequate time were afforded for the taking of medical opinion; especially was a proper investigation necessary of the conditions under which much medical practice was performed in this country. Such an investigation would have taken note of the capital sunk in the purchase of practices and of the income derivable in certain proportion from contract practice and in certain proportion from private patients; it would have estimated the amount of ground that a practitioner could cover in fairness to himself and in relation to his income; it would have ascertained the proper proportional number of the profession to the general population; it would have sifted the statements of those who proposed to adopt a measure for the English, Scottish, and Irish because it did (or did not) suit Germany. Such an investigation as this, made by people on whom the medical profession could rely, was wanted; for it was a revolution in medical practice and not an adjustment of our earning arrangements that was contemplated under the Bill.

But no. No stand was made by the medical profession for the necessary time in which to consider the Bill, although from the first it was clear that unless proper time was given the situation in which now we are placed would probably occur. Those in actual practice of the sort that must be affected were as little consulted as those having charge of the medical education of the country, or representing great medical corporations or great university faculties. A majority of medical men was found to believe that there was no peril in accepting the Bill in detail as well as in principle, if certain modifications were introduced. Of course, every man in this majority of medical men who demanded the recognition of what are called the six cardinal points was not solidly in favour of demanding all six points for the same reasons or with the same fervour-a weaknesis which could hardly fail to escape the eye of those responsible in Parliament for the passage of the Bill. The opposition to details was itself detailed. Similarly it was clear to all with experience of affairs that at least one of these six cardinal points would not be granted as such, or, at any rate, would not be incorporated in the Bill as such. But the prepossession in favour of the Bill, due to the excellent principles underlying it, no less than the excellent things in it, obscured many eyes. As the circular of the British Medical Association dated Dec. 11th, and published on p. 1726 of this issue of THE LANCET, shows, the Association decided on June 1st to adopt the policy expressed in the six cardinal points which have so often been set out. Given these points the Association decided to help in the working of the Bill, a policy which it is claimed is absolutely unchanged. Moreover, it is stated by the chairman of Representative meetings and the chairman of the Council of the Association to have been successful, in that by the efforts of the Association the Bill has now been so amended that there is no legal barrier against the profession securing the fulfilment of its entire policy as indicated by the six cardinal points. That may be so, but it would certainly require a lawyer to make this statement absolute; and we fear that any of our readers, desiring in a dispute to obtain the rights which he might thus believe to be reserved for him, would have considerable difficulty.

The position then is that a Bill, which no medical man should have wanted until it had been entirely adjusted upon professional lines and with due regard to existing conditions, will become law in a few days; that instead of such wholesale adjustment a policy of detailed amendments has been adopted by a majority of the medical profession; but that the measure is passing into law without there being any certainty that the very points are included concerning which the majority of the medical profession are, or rather are supposed to be, solidly positive. We can hardly wonder that the apprehensions of the profession are finding vent in such important meetings as that which is being held in Manchester as we go to press, and that which is announced to be held in London on Tuesday next under the chairmanship of Sir W. WATsON Cheyne. We hope that the collective force and wisdom of these meetings-and there will be many like them-will not be dissipated in mere bewailing of the present conditions, or in resentment at any particular persons or institutions. The energies of those who promote them and those who are present at them can well be turned to action, either by the strengthening of such organisation as we have, or by the formation of some representative, if temporary, authority, which, by taking a line of independent criticism, may 